\title{
O monstro contemporâneo: notas sobre a construção da pedofilia como "causa política" $e$ "caso de polícia"*
}

Laura Lowenkron $^{* *}$

\section{Resumo}

Baseado em uma etnografia da Comissão Parlamentar de Inquérito (CPI) da Pedofilia, no Senado Federal brasileiro, e das investigações da Polícia Federal em torno das redes de pornografia infantil na internet, o objetivo do artigo é analisar as correlações entre a construção da "pedofilia" como causa política e caso de polícia e a consequente produção do "pedófilo" como novo monstro contemporâneo. Na arena pública da CPI, especial atenção é conferida à centralidade das emoções e ao uso político das imagens de pornografia infantil. Nas investigações policiais, por sua vez, o foco é direcionado para a ação policial de identificação dos "fatos" e incriminação do "culpado". Por fim, é discutida a hipótese de que os principais "alvos" da "cruzada antipedofilia" são responsabilizados não tanto pelo que eles fazem (divulgar, trocar, distribuir ou adquirir, possuir, armazenar imagens pornográficas envolvendo menores de idade), mas pelo que suas ações revelam sobre seus desejos $e$ os perigos que estes representam, sugerindo que esse é um dos principais motivos que explicam a frequente confusão e sobreposição das categorias "pornografia infantil na internet" e "pedofilia" nos discursos públicos.

Palavras-chave: Pedofilia, Pornografia Infantil, Política, Polícia.

\footnotetext{
" Recebido para publicação em 27 de setembro de 2011, aceito em 12 de dezembro de 2012. O artigo é baseado na pesquisa de tese de doutorado (Lowenkron, 2012) desenvolvida no âmbito do Programa de Pós-Graduação em Antropologia Social do Museu Nacional/UFRJ sob a orientação da professora Adriana Vianna e com bolsa do CNPq.

*** Pós-doutoranda no Núcleo de Estudos de Gênero - Pagu/Unicamp, com financiamento da FAPESP. lauralowenkron@uol.com.br
}

cadernos pagu (41), julho-dezembro de 2013:303-337. 
O monstro contemporâneo

The Contemporary Monster: Notes on the Construction of Pedophilia as both a "Political Cause" and a "Police Case"

\begin{abstract}
Based on an ethnographic fieldwork carried out within the Parliamentary Inquiry Committee (PIC) on Pedophilia, in the Brazilian Federal Senate, and the police inquiries of the Federal Police Department, the aim of this paper is to analyze the interconnection between the construction of "pedophilia" as both a political cause and a police case and the consequent production of the "pedophile" as the contemporary monster. In the ethnographic description of the public arena of the PIC, special attention is conferred to the centrality of emotions and to the political use of the images of child pornography. In the police investigations, on the other hand, the focus is directed to the police action of identification of "facts" and incrimination of the "culprit". Finally, it is suggested that the main "targets" of this "antipedophilia crusade" are blamed not so much for what they do (share, distribute, acquire, possess or store pornographic images involving minors), but because of the dangers associated with their desires. The hypothesis of the paper is that this is the main reason for the common confusion between "child pornography on the internet" and "pedophilia" in the public discourses.
\end{abstract}

Key Words: Pedophilia, Child Pornography, Politics, Police. 
Contra os maus, dia e noite lutamos, resguardando a sagrada família. (trecho do Hino da Polícia Federal)

Em 20 de dezembro de 2007, a Polícia Federal, em parceria com a Interpol, deflagrou a Operação Carrossel, com o objetivo de combater a pornografia infantil na rede mundial de computadores. Essa foi a primeira operação internacional de combate à "pedofilia na internet" planejada e executada sob o comando da Polícia Federal brasileira. A ação envolveu 102 buscas e apreensões em 14 estados brasileiros e no Distrito Federal, além de ações policiais em outros 78 países. A Operação Carrossel, ou melhor, a notícia sobre a Operação Carrossel é um marco importante para iniciar a apresentação deste artigo, porque serviu de ponto de partida para a instauração da CPI da Pedofilia, no Senado Federal, e também para o meu projeto de pesquisa de doutorado.

Como tantas outras ações da Polícia Federal, a notícia sobre a Operação Carrossel foi divulgada nos principais veículos de comunicação do país. Na mesma época, eu formulava o meu projeto de doutorado, cujo tema era a construção social da pedofilia enquanto novo modelo de monstruosidade contemporânea ${ }^{1}$, e buscava estratégias etnográficas profícuas para a pesquisa. Foi ao ler a matéria no jornal sobre a Operação Carrossel que despertei para a importância do trabalho da Polícia Federal para a construção do "problema social" da "pedofilia", pois percebi que é a partir das investigações policiais que as chamadas "redes de pedofilia na internet" são traçadas $e$ reveladas ao público.

\footnotetext{
1 A noção de "monstruosidade" é aqui entendida de acordo com a definição de Foucault (2001). Segundo o autor, a figura do monstro é o grande modelo de todas as pequenas discrepâncias, é o limite mais extremo de toda anomalia, combinando o proibido e o ininteligível, transgredindo os limites não só da lei, mas da classificação.
} 
Também em meados de dezembro de 2007, o Senador Magno Malta ${ }^{2}$ apresentou um requerimento para a criação de uma Comissão Parlamentar de Inquérito (CPI) no Senado Federal "com o objetivo de investigar e apurar a utilização da internet para prática de crimes de pedofilia" (Requerimento n 200 de 2008, do Senado Federal). Um dos requisitos legais para a criação de uma CPI é que haja um "fato determinado" ( $\$ 3^{\circ}$, art. 58 da $\left.\mathrm{CF} / 88\right) .^{3}$ Entrevistei o assessor técnico da CPI da Pedofilia que, a pedido do Senador Magno Malta, foi quem elaborou o requerimento para a sua criação. Ele conta que a Operação Carrossel era a peça que faltava para a formulação da proposição, que foi lida no plenário do Senado no dia 4 de março de 2008, apresentando em sua justificativa que:

\begin{abstract}
A partir dos resultados da operação referida, aparecerão imagens e informações que, com certeza, chocarão a sociedade brasileira, mas que, concomitantemente, constituirão subsídios para despertar a maior atenção dos órgãos governamentais para que seja aprimorada a legislação pertinente, e também meios para educar $e$ prevenir a sociedade sobre essa sórdida prática que é a pedofilia (Diário do Senado Federal, 5 de março de 2008).
\end{abstract}

\footnotetext{
2 Um dos líderes da bancada evangélica, o parlamentar é conhecido como um dos principais opositores de uma série de reivindicações associadas à agenda dos chamados "direitos sexuais" no Congresso Nacional, como a legalização do aborto, a união civil dos homossexuais e a criminalização da homofobia. Enquanto Deputado Federal, ganhou destaque por sua atuação no combate ao crime organizado, como presidente da CPI do Narcotráfico. É também defensor ferrenho da redução da maioridade penal de 18 para 16 anos.

${ }^{3}$ Art. 58 da Constituição Federal. $\S 3^{\circ}$ "As comissões parlamentares de inquérito, que terão poderes de investigação próprios das autoridades judiciais, além de outros previstos nos regimentos das respectivas Casas, serão criadas pela Câmara dos Deputados e pelo Senado Federal, em conjunto ou separadamente, mediante requerimento de um terço de seus membros, para a apuração de fato determinado e por prazo certo, sendo suas conclusões, se for o caso, encaminhadas ao Ministério Público, para que promova a responsabilidade civil ou criminal dos infratores".
} 
Como é possivel perceber a partir das conexões apontadas entre a operação policial de combate à "pornografia infantil na internet" e a instalação de uma Comissão Parlamentar de Inquérito da "pedofilia", os termos se confundem nos discursos públicos. Vale notar que a "pedofilia" não constitui crime no Brasil, sendo originalmente uma categoria diagnóstica da psiquiatria associada à presença de desejos e fantasias sexuais envolvendo crianças pré-púberes. ${ }^{4}$ No entanto, na última década, o termo "pedofilia" tem sido cada vez mais utilizado por políticos, operadores do direito e pela imprensa para se referir a um conjunto de condutas criminosas relacionadas a práticas sexuais envolvendo menores de idade $e$, em especial, aos crimes relacionados à circulação de pornografia infantil via internet, definidos no Estatuto da Criança e do Adolescente (ECA/1990). "Tipificar a pedofilia" era um dos principais objetivos do Senador Magno Malta no início dessa CPI. No entanto, essa intenção não foi incorporada aos projetos de lei formulados no âmbito da CPI da Pedofilia, devido à reprovação de diversos membros do grupo de trabalho responsável por prestar assessoria técnica à comissão. ${ }^{5}$

${ }^{4}$ A Classificação Internacional de Doenças (CID-10), da Organização Mundial de Saúde (OMS), item F65.4, define a pedofilia como uma modalidade de "Transtorno de preferência sexual", caracterizado pela "preferência sexual por crianças, quer se trate de meninos, meninas ou de crianças de um ou do outro sexo, geralmente pré-púberes ou no início da puberdade". De acordo com o DSM IV-TR (Manual de diagnóstico de transtornos mentais da Associação Americana de Psiquiatria), a pedofilia é classificada como uma modalidade de "parafilia", caracterizada pelo foco do interesse sexual em crianças pré-púberes (geralmente, com 13 anos ou menos) por parte de indivíduos com 16 anos ou mais e que sejam ao menos cinco anos mais velhos que a criança, ao longo de um período mínimo de seis meses. O diagnóstico de pedofilia pode ser feito, segundo o manual, se a pessoa realizou esses desejos ou se os desejos ou fantasias sexuais causaram acentuado sofrimento ou dificuldades interpessoais.

${ }^{5}$ Em outro artigo (Lowenkron, 2010), realizo uma análise mais aprofundada sobre as diferentes categorias utilizadas para denominar as violências sexuais contra crianças e adolescentes, bem como apresento um relato sobre a controvérsia relativa à inclusão da categoria "pedofilia" em um dos projetos de lei 
Proponho que para compreender o privilégio da palavra "pedofilia" para se referir ao fenômeno da pornografia infantil na internet é importante situar os seus usos em meio a um conjunto de enunciados e práticas que participam da construção social da figura de um inimigo a ser perseguido: o "pedófilo". Minha hipótese é que essa confusão de termos e conceitos ocorre devido ao fato de a pornografia borrar as fronteiras entre fantasias, desejos e práticas sexuais, de modo a favorecer um deslocamento da atenção dos atos criminosos $e$ os danos que eles produziram para os sujeitos anormais e os perigos que eles representam.

Neste artigo, analiso parte do material coletado durante a minha pesquisa de campo junto à CPI da Pedofilia, no Senado Federal (entre março de 2008 e dezembro de 2010), e no Departamento de Polícia Federal (de março de 2009 a dezembro de 2010). O objetivo é ilustrar alguns dos mecanismos e efeitos da "cruzada antipedofilia" - como definiu o Senador Magno Malta nos contextos político e criminal brasileiros. As estratégias de ambos os órgãos serão analisadas na medida em que elas juntas são responsáveis pela fabricação dessa "cruzada" (por meio da politização e da criminalização) enquanto "causa" coletiva $e$ unânime. A ideia é analisar a especificidade de cada uma dessas estratégias e a forma pela qual elas se interconectam, tendo como foco a análise da construção da denúncia $e$ os seus desdobramentos, uma dinâmica que parece central na fabricação da "causa" e na produção de um engajamento coletivo em torno dela (Boltanski el al, 1984; Boltanski, 1993).

\section{CPI da Pedofilia: arena pública das emoções}

Se a Operação Carrossel forneceu o elemento que faltava, um "fato determinado", para a elaboração do requerimento da CPI da Pedofilia, é claro que não foi exclusivamente a partir desse

apresentado pela CPI da Pedofilia, que é discutida em detalhes no capítulo 4 de minha tese de doutorado (Lowenkron, 2012). 
fato e nem da noite para o dia que o senador Magno Malta, presidente da Comissão, envolveu-se com o tema. Em entrevista, o senador narrou-me o processo de como surgiu seu interesse pela questão:

Quando eu fui deputado federal na presidência da CPI do narcotráfico eu denunciei isso no relatório da CPI do narcotráfico (...). Eu havia detectado naquela época que havia narcotraficantes tomando crianças para abuso e com a força do fuzil e a força do dinheiro. (...) É uma questão que a mim comovia muito e me deixava muito angustiado. Então, quando cheguei aqui na Casa [Senado Federal], nos últimos quatro anos eu só subia na tribuna para falar disso. E comecei a perceber que a coisa era muito grande porque eu me tornei uma espécie de delegacia do Brasil e Delegado do Brasil. As pessoas mandavam tudo para mim. (...). Depois, o Ministério Público começou a me acionar. (...) Então, eu um dia mandei a assessoria escrever o "fato determinado" e criei essa CPI. Quando eu quis criar essa $\mathrm{CPI} e$ fui buscar assinatura, os senadores não queriam assinar, que isso não existia, que era muito pouco, que de vez em quando que a gente via um caso (...). Mas o Ministério Público me mandou imagens e me mandou uma última imagem para a minha tomada de decisão ali. Era um homem de 70 anos tendo conjunção carnal com uma criança de quatro anos de idade. E eu saí nos gabinetes, conversando com os senadores e, quando eles não queriam assinar, eu mostrava a imagem. E eles entravam em desespero porque todo mundo é pai. Então, o que o olho não vê o coração não sente, mas o que vê, sente. As pessoas foram entrando em desespero e eu fui dizendo: eu vou mostrar a vocês o que é um monstro.

Nota-se que os sentimentos de "comoção" $e$ "angústia" diante da descoberta dos fatos e, principalmente, frente às imagens de "abusos sexuais de crianças" são apontadas pelo senador como principal força motriz para o seu engajamento 
político em relação à "causa" e para a criação da CPI. Como sugere Boltanski (1993), parte das estratégias de construção de si enquanto porta-voz legítimo do sofrimento alheio implica em demonstrar a autenticidade do seu engajamento. Ao enfatizar a emoção enquanto vetor determinante para a adesão à luta contra a "pedofilia", Magno Malta assinala que sua atuação não é movida por interesses pessoais de lucro político, mas por uma compaixão profunda, sincera e generosa em relação à dor das "crianças abusadas".

Não interessa avaliar aqui a autenticidade das emoções $e$ dos motivos apontados pelo senador para o seu engajamento na "causa", mas apenas introduzir uma questão que me parece fundamental para pensar as discussões políticas em torno da "infância", em geral, e da "violência sexual contra crianças", em particular, que é o fato desses discursos estarem inseridos em um campo político profundamente marcado pela obrigação moral de expressar emoções (Mauss, 1980) ${ }^{6}$ e de exibir um interesse desinteressado, nos termos de Bourdieu (1996).

Diversas vezes o presidente da CPI da Pedofilia reafirma esse interesse desinteressado ao delimitar a fronteira entre essa CPI, baseada em interesses comuns, e outras "CPIs de governo", baseadas em interesses político-partidários específicos. Ele afirma que essa não é uma CPI de partido, de disputa política, mas uma CPI da "sociedade", das "crianças", da "família", procurando apresentar a sua "causa" como uma luta voltada para um bem coletivo e unânime. Nos termos do senador Demóstenes Torres,

\footnotetext{
6 Ao tomar como objeto de análise um ritual funerário no texto "A expressão obrigatória dos sentimentos", publicado originalmente em 1921, Mauss foi um dos primeiros autores a chamar a atenção para as dimensões ritual e social da expressão das emoções, que até então eram tomadas meramente como respostas "naturais" e "espontâneas" a determinados eventos. No termos do autor: "Não apenas o choro, mas toda sorte de expressões orais dos sentimentos são, não fenômenos exclusivamente psicológicos ou fisiológicos, mas fenômenos sociais marcados, eminentemente, pelo signo da não-espontaneidade e da mais perfeita obrigação" (Mauss, 1980:56).
} 
relator da CPI da Pedofilia, "essa é uma CPI que não tem oposição, não tem governo, não tem interesses políticos subjacentes".

Não se pode ignorar (e é claro que nenhum político ignora) que a "infância" $e$, principalmente, as injustiças cometidas contra as crianças constituem um território moral politicamente muito lucrativo para aqueles que conseguem se legitimar como representantes da luta contra essas injustiças. Contudo, a exibição convincente do desinteresse e do altruísmo é condição de possibilidade para obtenção desse lucro simbólico. Vale destacar que a consciência do lucro simbólico não invalida a virtude do engajamento político na "causa". Ao contrário: o fato de haver lucros na virtude é um dos grandes motores da virtude na história (Bourdieu, 1996:154).

Até aqui, destaquei a importância da exibição das emoções para a configuração de um engajamento desinteressado e altruísta que é necessário para que o senador Magno Malta possa reivindicar a condição de porta-voz legítimo da "causa". Essa estratégia retórica remete à noção de "usos táticos da paixão" proposta por Bailey, segundo a qual "a exibição das emoções é (entre outras coisas) também modos de suscitar confiança"7 (Bailey, 1983:12). O autor destaca ainda que as emoções são dispositivos para persuasão e desempenham um papel mais importante do que a razão em governar as pessoas. Nesse sentido,

\footnotetext{
7 Evidentemente, a expressão da emoção, se não for reconhecida como "autêntica" e "sincera", mas sim como "tática" e "retórica" pode também ser desqualificada pela audiência e suscitar desconfiança, como aponta Bailey (1983). No espaço político, discursos emotivos como os de Magno Malta são frequentemente interpretados como "retórica sensacionalista", tornando-se objeto de desconfiança e reprovação de parte do público, como, nesse caso, de políticos e militantes que já tinham uma trajetória em relação à "causa" da defesa dos direitos de crianças e adolescentes, como membros da Secretaria de Direitos Humanos da Presidência da República. No entanto, os comentários críticos à CPI da Pedofilia restringiram-se aos bastidores. Na cena pública, parece prevalecer um acordo tácito entre os políticos de que o "tom" apropriado para falar sobre o tema da "violência sexual contra crianças" é a retórica emotiva, ainda que a sua intensidade e a sua forma possam variar.
} 
outro elemento fundamental para a construção dessa "causa" política, além da produção da figura de um porta-voz moralmente legítimo, foi a sua capacidade de persuadir outros parlamentares a o apoiarem nessa "cruzada". 8

Elaborado o requerimento, em pouco tempo Magno Malta conseguiu as assinaturas necessárias para instalação da comissão parlamentar de inquérito. Para reunir um coletivo em torno de sua "causa", o senador precisou desencadear um processo de contágio de emoções (Boltanski, 1993:123). Passo a analisar, portanto, como a retórica das emoções e o impacto emotivo das imagens de pornografia infantil desempenharam um lugar central na denúncia pública que serviu de base para a construção da "causa".

No livro "Diante da Dor dos Outros", Susan Sontag discute o impacto das fotografias de guerra e de sofrimento nos espectadores à distância. A autora atribui às fotos uma especial força de agência emotiva, ao sugerir que elas funcionam como totens privilegiados de causas, afirmando que "um sentimento tem mais chance de se cristalizar em torno de uma foto do que de um lema verbal" (Sontag, 2003:72). Ao longo da CPI da Pedofilia, fica evidente que aqueles que eram expostos aos relatos ou à observação direta das fotografias e dos vídeos de pornografia infantil não poderiam reagir de outra forma a não ser por meio da expressão de "horror" e "indignação", que é interpretada pelos parlamentes da comissão como um primeiro estágio de adesão subjetiva à "causa", seguido da expectativa e da exigência de alguma forma de ação política.

A centralidade das imagens na construção da "causa" pode ser percebida de maneira exemplar no relato do senador Magno

8 Como sugere Bourdieu (1989), no campo político, diferentemente do que no campo da ciência, "a força das ideias que ele [o porta-voz do grupo] propõe mede-se, não pelo valor de verdade (mesmo que elas devam uma parte da sua força à sua capacidade para convencer de que detém a verdade), mas sim pela força de mobilização que encerram, quer dizer, pela força do grupo que as reconhece, nem que seja pelo silêncio ou pela ausência de desmentido, e que ele pode manifestar recolhendo as suas vozes ou reunindo-as no espaço" (Ib.:185). 
Malta apresentado acima. Em sua narrativa, o presidente da CPI da Pedofilia estabelece uma espécie de momento mítico-originário sobre o seu processo pessoal de conversão emotiva que serviu de base para o seu engajamento político na "causa". Segundo Magno Malta, a imagem de um homem de 70 anos tendo conjunção carnal com uma criança de quatro anos foi decisiva para retirá-lo do estado passivo de comoção, levando-o a "sair pelos gabinetes" a fim de mobilizar os demais senadores para a instalação da CPI da Pedofilia.

Nesse sentido, a imagem foi determinante para a passagem da compaixão para a indignação, nos temos de Boltanski (1993:91), o que implica em converter o sofrimento particular em sofrimento coletivo e, no momento seguinte, em denúncia pública. É em direção ao culpado que se orienta a indignação, que vai se desdobrar em denúncia $e$ dar origem a um inquérito (Boltanski,1993:101). Com isso, a atenção desloca-se da vítima ("criança abusada"), que suscita compaixão, para o "pedófilo", que desperta ódio. Nas palavras do senador:

\begin{abstract}
Em alguns momentos não é indignação, é ódio mesmo. Eu não posso esconder isso. E eu que sou um homem cristão, agradeço a Deus por isso, mas tenho vivido há um ano e dois meses uma dificuldade com Deus porque não acredito na recuperação dessa gente. Não acredito, sabe? São compulsivos, desgraçados, insaciáveis. Sabe? E a gente não pode negar o que a gente sente. Não pode sair por aí incitando as pessoas a cometerem violência. Mas quando você olha a imagem de um pai abusando uma criança no berço, a sua vontade é que ele morra. (senador Magno Malta, em entrevista)
\end{abstract}

A eficácia da sensibilização estética a partir do contato direto com a cena de horror é tanto maior quanto mais jovem for a criança na foto e mais violenta for a cena de sexo. As imagens de estupro de bebês ou cenas de crianças de tenra idade envolvidas em diversos tipos de interações sexuais com adultos funcionam, 
assim, como dispositivo de sensibilização particularmente eficaz ao qual o presidente da CPI frequentemente recorre. Ele não apenas descreve as imagens (que não podem ser exibidas publicamente) durante as audiências públicas da CPI, como também mostra as fotos, reservadamente, para todos aqueles que pretende mobilizar: juízes, representantes das empresas de provedores de internet $e$ operadoras de telefonia, senadores, deputados e até o Presidente da República. O impacto das imagens parece empolgá-lo ao reforçar a eficácia de sua estratégia de sensibilização:

Eu estive no Tribunal de Justiça de São Paulo, com quase 50 desembargadores, homens maduros, avôs, e quando eu abri a terceira imagem, eu nunca pensei ver um quadro daquele, de ver quase 50 homens chorando, desesperados, e um assume a palavra e fala em nome dos outros, dizendo: "Aqui não sai liminar para pedófilo, e a nossa posição está definida". E cresceu uma coisa no meu coração aquele dia: eu vou andar os Tribunais de Justiça do Brasil inteiro; eu vou a todos os estados; eu quero mostrar aos desembargadores essas imagens; eu vou a cada gabinete do Supremo levar essas imagens. (Magno Malta, em audiência pública da CPI da Pedofilia, 17/06/08).

$\mathrm{O}$ quadro de 50 desembargadores chorando, acionado por Magno Malta, exerce nos espectadores da audiência pública da CPI um efeito moral bastante significativo, ao mostrar que as imagens são tão chocantes que são capazes de fazer até homens maduros e poderosos irem às lágrimas. Vale destacar que, ao subverter as expectativas sociais de exibição dos sentimentos em relação ao gênero e à posição social dos agentes, o quadro dá ainda mais força à pedagogia política dos sentimentos utilizada pelo presidente da CPI da Pedofilia.

$\mathrm{O}$ senador argumenta que as imagens não funcionam apenas como um dispositivo de choque, mas servem também para conscientizar as pessoas sobre a "realidade da pedofilia". Segundo ele, as pessoas imaginam que pedofilia é sempre um 
homem abusando de uma menina de 13 ou 14 anos, não imaginam meninos, não imaginam bebês, o que parece, na sua afirmação, ser considerado por ele algo mais grave e/ou chocante.

\begin{abstract}
O sujeito pensa "pedofilia", o sujeito imagina um homem adulto tendo relação com uma menina de 13, 14 anos de idade. A sua mente nunca lhe dá uma menina ou um menino de um ano, seis meses, uma criança de três anos fazendo sexo com dois homens. Um pai penetrando uma criança de um ano de idade. Um padre abusando de uma criança ou um pediatra estuprando com a boca uma criança com 22 dias de nascida (senador Magno Malta, em entrevista)
\end{abstract}

$\mathrm{O}$ repertório de aberrações constantemente evocado na $\mathrm{CPI}$ da Pedofilia importa menos pelos casos singulares e localizados que denuncia do que por funcionarem como exemplares de um problema mais geral, servindo de suporte para a construção de uma "causa" política e de uma denúncia pública (Boltanski, 1993:27-28). Os corpos e dramas particulares convocam a compaixão do espectador ao mesmo tempo em que são agregados e interpretados a partir de um princípio de inteligibilidade comum que, no caso, situa-se entre o criminoso e o patológico.

Vale destacar que, na CPI, a "pedofilia" é entendida como sinônimo de crimes sexuais contra crianças e adolescentes, em especial, aqueles praticados através da internet. Nos discursos dos senadores da CPI, a "pedofilia" aparece como um "crime", uma "tara", um "vício" e uma "chaga", e os "pedófilos" como "criminosos desgraçados", "compulsivos", "insaciáveis" e "monstros". Na matemática do presidente da comissão: "para mim, a pedofilia é $5 \%$ de doença e $95 \%$ de safadeza". Ao explicar, ele afirma que "o sujeito que por causa da sua lascívia invade uma criança, não me venha dar de doidinho. Vai ter que ir para a cadeia". Ou seja, mais do que uma condição doentia, a 
"pedofilia" é entendida como uma "condição anormal permanente e irreversível", nos termos de Carrara (1996:59). ${ }^{9}$

Frequentemente, nas audiências públicas da $\mathrm{CPI}$ da Pedofilia, são citados diversos casos a partir dos quais emerge um sentido de monstruosidade geral. Além das já citadas imagens e cenas de pornografia infantil, os parlamentares acionam, nos discursos públicos, denúncias das quais tomam conhecimento a partir da rede de colaboradores da CPI (Polícia Federal, Ministério Público, ONG Safernet, emails de cidadãos comuns etc.) ou a partir de escândalos de "pedofilia" veiculados na imprensa e já conhecidos pelo público e que, muitas vezes, também passam a ser objeto de investigação da $\mathrm{CPI}$.

Ao tomar conhecimento dessa "realidade da pedofilia", construída a partir de casos e imagens, não resta ao observador do "espetáculo do sofrimento" outra alternativa a não ser engajarse na "causa", pois, como sugere Boltanski (1993:38-39), ao omitirse, poderia ser acusado (ou acusar-se a si mesmo) de responsabilidade passiva por indiferença ou, até mesmo, por cumplicidade com o causador direto do sofrimento das "crianças abusadas", o "pedófilo".

Além de ter poderes de investigação próprios das autoridades judiciais ( $\$ 3^{\circ}$, Art. 58 da $\mathrm{CF} / 88$ ), a CPI tinha como um de seus objetivos dar visibilidade ao tema, no que foi muito bem sucedida. $\mathrm{Na}$ avaliação da coordenadora da área penal da Secretaria de Assuntos Legislativos do Ministério da Justiça, o forte apelo à mídia que caracterizou a CPI da Pedofilia deve-se tanto ao tema quanto à atuação de Magno Malta como presidente dessa comissão. "Ele tem uma capacidade muito grande de manter o assunto na mídia", diz ela.

Ao lado da importância de mobilizar e reunir "Todos Contra a Pedofilia" - nome da campanha nacional criada a partir da CPI -, os parlamentares apostavam no efeito coercitivo dessa

9 O autor refere-se não aos pedófilos do século XXI, mas à maneira pela qual eram concebidos os degenerados do século XIX. 
visibilidade, como se pode notar na fala do senador Geraldo Mesquita, na primeira reunião da comissão: "Essa CPI, entre outros papéis, cumprirá o papel de se transformar numa grande vitrine para constranger, de fato, para, sobretudo constranger, para inibir, para constranger e, futuramente, para punir".

Apesar de a espetacularização ser um elemento chave da $\mathrm{CPI}$, é preciso lembrar que, enquanto dispositivo do poder legislativo, um dos resultados esperados dos levantamentos realizados pela comissão é a formulação de projetos de lei que sirvam para aprimorar a regulação do problema em pauta. Nesse sentido, uma conquista de suma importância para o sucesso político da CPI foi a aprovação, em tempo recorde, da Lei $n^{\circ}$ 11.829 de 2008, que alterou o Estatuto da Criança e do Adolescente. Além de tipificar a posse e o armazenamento de material pornográfico infanto-juvenil, o aliciamento e o assédio on-line de crianças (menores de 12 anos) e a foto ou vídeomontagem que simule a participação de menores de 18 anos em cenas pornográficas, a nova lei aumentou as penas para os crimes relacionados à produção, venda e distribuição de pornografia infanto-juvenil.

Outro ponto que merece ser destacado é a composição da CPI da Pedofilia. Além dos parlamentares e seus assessores, a comissão reuniu um grupo de trabalho composto por delegados de Polícia Federal, membros dos Ministérios Públicos Federal e Estadual, além do advogado e do presidente da ONG Safernet. Os representantes desses diferentes órgãos e entidade participaram da delimitação do foco de atuação da comissão, a saber: resolver os entraves que esses órgãos enfrentavam no combate à pornografia infantil na internet, devido, principalmente, a lacunas legislativas $e$ falta de cooperação dos provedores de internet $e$ operadoras de telefonia. A principal lacuna legislativa apontada no início da CPI era o fato de não existir uma tipificação das condutas de posse $e$ armazenamento de material pornográfico infantil.

Com relação à falta de cooperação dos provedores de internet e operadoras de telefonia, o que acontecia é que essas 
empresas não atendiam em tempo hábil as ordens da justiça brasileira de quebra de sigilo telemático e de fornecimento de dados cadastrais dos usuários suspeitos de estarem disponibilizando imagens de pornografia infantil na rede mundial de computadores, o que inviabilizava muitas das investigações. Os representantes da maior parte dessas empresas argumentavam que as imagens ficavam hospedadas em um provedor situado em outro país, de modo que o controle das informações nele contidas estava subordinado à justiça daquele local.

Nesse sentido, a CPI também obteve avanços significativos, a partir da assinatura dos TACs (Termos de Ajustamento de Conduta), que delimitaram prazos e obrigações para as empresas de telecomunicações com filiais no Brasil atenderem às demandas das autoridades públicas brasileiras. O principal marco foi a assinatura do TAC com a Google e, a partir disso, a quebra de sigilo dos álbuns do Orkut - rede social virtual ligada à empresa Google - que era, de acordo com a ONG Safernet, o principal lócus de pornografia infantil na internet entre os brasileiros, ou seja, sítio ao qual se referia a maior quantidade de denúncias.

A quebra de sigilo dos álbuns do Orkut deu origem a uma nova operação da Polícia Federal, a Operação Turko (anagrama de Orkut), envolvendo 102 buscas e apreensões em 20 estados brasileiros e no Distrito Federal. Deflagrada em 18 de maio de 2009, Dia Nacional do Combate ao Abuso e Exploração Sexual de Crianças e Adolescentes, a Operação Turko foi resultado direto dos trabalhos da CPI da Pedofilia e foi a primeira ação da Polícia Federal a realizar prisões em flagrante pelo novo crime de posse de material pornográfico infantil.

Mais uma vez, observa-se a circularidade $e$ a interdependência das atuações da CPI da Pedofilia e da Polícia Federal no enfrentamento da "pedofilia na internet". Apesar de influenciarem-se mutuamente, as estratégias e os desdobramentos das investigações conduzidas pela $\mathrm{CPI}$ e pela $\mathrm{PF}$ não são os mesmos. Até aqui, procurei analisar as estratégias da CPI da Pedofilia para a politização do tema, ou seja, para a construção da 
pedofilia enquanto "causa" política. Destaquei a capacidade de sensibilização - a capacidade de contagiar emocionalmente como um dos principais meios para mobilização de seguidores e a produção de um engajamento coletivo como um de seus principais efeitos.

Como afirmam Boltanski et al (1984:4), "as causas constituídas são sempre associadas a grupos e podemos mostrar que um grande número de grupos se cristaliza em torno de uma causa". ${ }^{10}$ Portanto, ao reunir "Todos Contra a Pedofilia" políticos, órgãos estatais, organizações da sociedade civil, empresários, imprensa, "opinião pública" etc. -, a "causa" que a CPI da Pedofilia reivindicava representar era apresentada em nome de "todos os cidadãos de bem", que se constituem a partir de um inimigo comum.

Passo, agora, a abordar uma outra estratégia de enfrentamento da "pedofilia na internet", a partir da análise da instauração de inquéritos policiais.

\section{Inquérito policial: identificação de crimes e criminosos}

Quando fui a Brasília acompanhar a CPI da Pedofilia no Senado Federal, conheci os delegados de Polícia Federal que faziam parte do seu grupo de trabalho. Eles eram responsáveis pela coordenação nacional das operações da Polícia Federal no combate à "pedofilia na internet", atuando junto ao órgão central do Departamento de Polícia Federal (DPF), no Distrito Federal. Através desses delegados, fui encaminhada para a Delegacia de Defesa Institucional da Superintendência Regional do Rio de Janeiro (DELINST/SR/DPF/RJ), onde realizei minha pesquisa de campo junto ao Núcleo de Prevenção e Repressão a Crimes via Internet, o NUNET. Por meio da observação participante no NUNET e da consulta a inquéritos policiais, foi possível fazer uma etnografia

${ }^{10}$ Tradução minha. No original: "les causes constituées sont toujours associées à des groupes et on peut montrer qu'un grand nombre de groupes se sont cristallisées autour d'une cause". 
das investigações da Polícia Federal em torno dos crimes relacionados à circulação de pornografia infantil na internet.

As mediações feitas a partir do órgão central da Polícia Federal facilitaram bastante a entrada em campo na DELINST/RJ. Ainda assim, somente mediante autorizações judiciais é que pude ter acesso aos inquéritos policiais, pois a lei determina que esses documentos são sigilosos (art. 20 do $\mathrm{CPP} / 41)^{11}$, e nos processos referentes a crimes contra crianças é determinado "segredo de justiça”. Meu objeto de pesquisa era duplamente sigiloso.

Mesmo com a autorização judicial em mãos, a ideia de que estava transitando em uma "sociedade secreta" $e$ os riscos $e$ compromissos que isso envolve (Simmel, 1974) eram reforçados repetidas vezes durante a pesquisa de campo na delegacia. A cada vez que fazia alguma pergunta sobre operações policiais ainda não deflagradas, um dos agentes de Polícia Federal do NUNET repetia, em tom de brincadeira: "se eu te falar isso, vou ter que te matar".

Ao mesmo tempo, os policiais reconheciam a importância de dar publicidade à ação da PF através da imprensa, especialmente, em termos numéricos, para mostrar que os crimes estão sendo reprimidos. "Nós trabalhamos com a repressão, não com o fim somente de punição, mas, sim, com fins de prevenção. Nós queremos demonstrar ao criminoso que não é bom cometer esse crime porque ele vai ser identificado e vai ser punido", sintetiza, em entrevista, o chefe da Unidade de Repressão a Crimes Cibernéticos (URCC) do órgão central da Polícia Federal, em Brasília.

As atuações da PF podem ser divididas, basicamente, em duas modalidades: investigação e execução. Só depois que as operações são deflagradas, é que existe uma publicidade parcial sobre a atuação policial, preservando, ainda, os nomes dos envolvidos, bem como os procedimentos investigativos que permitiram detectar os "alvos". A discrição é recomendada até no

\footnotetext{
${ }^{11}$ Art. 20 do Código de Processo Penal. "A autoridade assegurará no inquérito o sigilo necessário à elucidação do fato ou exigido pelo interesse da sociedade".
} 
momento da busca e apreensão, a fim de preservar a reputação social daquele que ainda é apenas um suspeito.

Assim, ao contrário da investigação realizada pela CPI, na qual os holofotes da imprensa eram sempre vistos como aliados durante o processo, no inquérito policial o sigilo de todo o procedimento de investigação é considerado um elemento chave para o seu sucesso e, por isso, a relação com a imprensa é sempre tensa. Essa tensão aparecia também na relação com a própria CPI da Pedofilia.

Outra diferença crucial entre o inquérito conduzido pelos parlamentares e os inquéritos policiais é que enquanto no primeiro a emoção comparece como um elemento chave, no segundo os sentimentos devem ser afastados em favor das causas objetivas. Se o espaço político, como vimos, é voltado para a expressão e a produção de compaixão $e$ indignação, no inquérito policial a atenção volta-se para o mundo dos objetos a fim de fundar a acusação na realidade (Boltanski:1993).

Esse esfriamento pode ser percebido pelo relato dos agentes que avaliam as imagens de pornografia infantil sobre os seus diferentes estágios emocionais. Mobilizada frente às imagens exibidas no meu primeiro dia de pesquisa de campo, perguntei se eles não se sentiam mal de ficar olhando essas cenas. Eles responderam que, no início, há um misto de curiosidade $e$ choque. Depois, vem a tristeza e a revolta. Com o tempo, você acaba se acostumando e não se choca mais tanto, apesar de considerarem que isso não é bom. Nas palavras de um dos agentes do NUNET:

No início, dá uma curiosidade. Você fica querendo ver e depois diz: nossa, olha o que eles fazem... Isso existe... Depois, aquilo vira normal. Normal, não, mas faz parte da rotina, do trabalho. No terceiro estágio, você rotinizou tanto que começa a perder a sensibilidade, achar aquilo normal. Isso não é bom. Quando percebi isso, parei de olhar, passei a evitar olhar. 
Apesar do esfriamento necessário para realização do trabalho, é importante manifestar algum grau de repulsa ou, ao menos, de desinteresse frente às imagens, para que não recaia sobre eles a acusação de "pedofilia". Os próprios agentes do NUNET comentaram que achavam que havia muito "pedófilo enrustido": "Há muitos colegas aí que ficam olhando as fotos e dizem 'ai, que horror', e ficam olhando com a maior atenção, a maior curiosidade... Você vê que ele tá gostando...". Portanto, a aparente espontaneidade da repulsa e do desinteresse caminha lado a lado com um valor moral de profunda obrigação dessa expressão o que, por sua vez, não exclui a sinceridade. "Tudo isso é, ao mesmo tempo, social e obrigatório e, no entanto, violento e natural: afetação e expressão (...) andam juntas" (Mauss, 1980:60).

No entanto, como destaca Boltanski (1993:101), na fase do inquérito é preciso controlar a emoção, fazê-la calar, para ir às provas. $\mathrm{O}$ objetivo dos investigadores é reunir a maior quantidade de "evidências" (imagens de pornografia infantil) para ajudar a prender o "pedófilo". Para compreender o deslocamento dos sentimentos para os fatos, apresento as fases e os procedimentos das investigações policiais em torno da circulação da pornografia infantil na rede mundial de computadores.

O objetivo do inquérito policial é investigar a "materialidade" e a "autoria" de uma suposta prática criminosa que, no caso, é prevista no Estatuto da Criança e do Adolescente (ECA). Como os crimes cometidos contra crianças e adolescentes previstos no ECA são de "ação pública incondicionada" (art. 227 do ECA/90), qualquer cidadão indignado frente a uma imagem de pornografia infantil pode e deve denunciar os fatos às autoridades públicas, gerando uma "notícia crime".

$\mathrm{Na}$ maioria das vezes, a "notícia crime" parte de uma "denúncia anônima" feita através de diferentes canais de denúncia: o "disque 100", coordenado pela Secretaria de Direitos Humanos da Presidência da República (SDH/PR); a Central Nacional de Denúncias na internet, coordenada pela ONG Safernet; as denúncias feitas por email, telefone ou pessoalmente, 
junto ao Ministério Público, à Polícia Federal ou à Polícia Civil etc. Outra possibilidade é que a "notícia crime" seja comunicada via Interpol (Polícia Internacional), nos casos em que a participação de brasileiros é identificada em investigações policiais de outros países. Esses diferentes "canais de denúncia" encaminham a "notícia crime" para o órgão policial competente pela apuração. No Brasil, a investigação de crimes praticados via internet é competência da Polícia Federal, devido à natureza transnacional desses delitos. ${ }^{12}$ Além disso, a Polícia Federal pode iniciar uma investigação proativamente, a partir de monitoramente de sítios na internet $e$ redes de sociabilidade on-line.

Tanto a apuração da denúncia quanto a investigação de iniciativa dos próprios policiais são anteriores à instauração do inquérito e consistem em um trabalho social de selecionar as denúncias que contam $e$ as que não contam. Esse processo de filtro é a principal atribuição dos dois agentes de Polícia Federal (APFs) que formam a equipe do NUNET, que chamarei de APF Alfredo $e$ APF Richard. Eles constituem o primeiro ponto sensivel da cadeia nas investigações e apurações iniciadas nessa delegacia. Ou seja, a informação na qual a autoridade policial (delegado) vai basear-se para decidir se vai ou não instaurar um inquérito sobre "pedofilia na internet" depende da sensibilidade dos agentes do NUNET.

É importante, então, atentar para os critérios utilizados por eles para hierarquizar os denunciantes e as denúncias, avaliando os casos em que ela é considerada válida ou deve ser ignorada ou desqualificada (Boltanski et al, 1984:6). Primeiramente, existe uma hierarquia dos denunciantes que não podem ser ignorados. Por mais que a denúncia pareça infértil, quando ela é encaminha pelo

\footnotetext{
${ }^{12}$ Os crimes cibernéticos tendem a ter uma natureza transnacional devido às características do meio. A internet é uma rede que conecta, direta (sistema "ponto-a-ponto") ou indiretamente (via provedor), pessoas situadas em diversos pontos do planeta. Um usuário situado no Brasil pode disponibilizar dados (como texto, música, foto e vídeo) a partir de um servidor situado em território estrangeiro. Esses dados, por sua vez, vão estar disponíveis para que usuários do mundo todo possam acessá-los.
} 
Ministério Público Federal, é exigida uma apuração e uma resposta que tem um prazo determinado. Existem também alguns denunciantes que se transformam em verdadeiros colaboradores, segundo o APF Richard:

Têm alguns colaboradores que quando vejo email dessa pessoa eu já leio com certeza, que geralmente é "coisa boa", entre aspas, coisa ruim. É crime configurado mesmo. Uma mulher fez disso uma cruzada pessoal dela, ela não faz outra coisa que não ficar varrendo internet $e$ ficar mandando pra gente. Então, quando é email dela a gente já olha com mais carinho.

Outro critério fundamental para decidir se a denúncia será ou não levada adiante consiste na verificação da "materialidade". Para isso, é preciso checar se a página de internet denunciada ainda está no ar. Se estiver, é preciso verificar se existe um "fato típico" (previsto na lei criminal), ou seja, se a imagem (foto ou vídeo) é ou não pornográfica e se pode ou não ser identificada a participação de menores de 18 anos na cena. Vale destacar que, de acordo com o artigo 241-E do Estatuto da Criança e do Adolescente:

Para efeitos dos crimes previstos nesta Lei, a expressão "cenas de sexo explícito ou pornográfica" compreende qualquer situação que envolva criança ou adolescente em atividades sexuais explícitas, reais ou simuladas, ou exibição dos órgãos genitais de uma criança ou adolescente para fins primordialmente sexuais.

Observa-se que, apesar de o legislador ter procurado precisar a definição de pornografia infantil, o texto legal ainda deixa brechas para interpretação no que diz respeito aos fins da imagem, a qual é sempre contextual, situacional e relacional. Certa vez, por exemplo, apareceram em um inquérito fotos de crianças nuas junto com um conjunto de imagens de adultos nus, em um contexto de "naturismo", de modo que não foi 
configurado o fim sexual da imagem e, por isso, na análise pericial ela não foi considerada "pornográfica". Assim, com o intuito de eliminar quaisquer resquícios de ambiguidade, os agentes priorizam as imagens de "abuso mesmo", que pode ser tanto o ato sexual envolvendo crianças, quanto uma performance com caráter explicitamente sexual, como é definido na fala do APF Richard:

A gente trabalha muito com a foto do abuso mesmo. Porque você pega uma criança numa foto "artística", o cara pode desqualificar no futuro dizendo que acha bonito o nu dos sete anos ou dez anos. Ainda mais se tiver nu de homens e mulheres de todas as idades, mas sem abuso sexual... Têm pais idiotas que fazem isso, tiram fotos dos filhos pelados e acham uma maravilha. (...) Mas se você pega uma foto de uma criança, não há abuso, mas uma foto ginecológica, o negócio já começou... Está havendo um abuso. Uma foto artística? Ah, uma menininha sem roupa, mas com um chapéu, com uma toquinha... Tudo bem, ainda pode ser considerado... Agora, quando pega uma menina, bota ela de quatro, bota braço pra trás, bota ela em posição de frango assado, aí já está caracterizado abuso.

Outro elemento fundamental para configurar a "materialidade" é a caracterização da menoridade da(s) pessoa(s) envolvida(s) na cena pornográfica. É importante destacar que, apesar de o texto da lei se basear na idade cronológica para a definição do delito (menor de 18 anos), no fenômeno da pornografia na internet, é extremamente difícil e raro identificar as crianças $e$ os adolescentes que aparecem nas imagens para saber ao certo suas idades. As fotografias e vídeos disseminam-se muito rapidamente pela rede mundial de computadores e, uma vez na internet, uma imagem antiga tende a voltar ou a continuar a ser divulgada a partir de qualquer ponto do planeta. Como destacam os policiais, é comum que as mesmas imagens apareçam em diferentes investigações nos mais diversos países e que fotos $e$ vídeos antigos permaneçam circulando na internet durante muito 
tempo. Desse modo, é praticamente impossível localizar o ponto zero de divulgação, o produtor das imagens $e$ as crianças e os adolescentes que nelas aparecem.

Na prática, para a configuração da "materialidade" do crime de pornografia infanto-juvenil, não basta ser menor, é preciso parecer que o é sem a menor sombra de dúvidas. Portanto, na pornografia infanto-juvenil na internet, a dimensão performativa da idade é particularmente evidente e eficaz, na medida em que se observa uma centralidade da estilização dos corpos e dos atos (Butler, 2003) ${ }^{13}$ na construção e substancialização das categorias etárias. Passo, então, a analisar o processo de eleição das marcas que importam para a caracterização da menoridade.

Segundo o APF Alfredo, eles utilizam um critério "objetivo" para definir a menoridade. Essa "objetividade" é baseada na sensibilidade estética dos agentes, que discutem entre si sobre as imagens observadas. Segundo Alfredo, quando há dúvida ou controvérsia é porque a menoridade é "subjetiva", o que não é suficiente enquanto prova judicial. Em alguns casos, não há qualquer margem de dúvida. Pergunto como se estabelece isso. Eles dizem que é o "senso comum". "Bebê ou criança de dois, três, cinco anos. Não há dúvida", afirma o APF Richard.

No entanto, há casos em que as fronteiras entre fantasia $e$ realidade, lícito e ilícito, normal e anormal são bastante tênues, de modo que, apesar de ser crime, é difícil configurar materialidade no caso de imagens pornográficas que envolvem meninos $e$ meninas situados na zona cinzenta da adolescência. Os agentes explicam que existem muitos sítios pornográficos na internet nos quais a menoridade, principalmente a feminina, é simulada, por ser valorizada no mercado do erotismo enquanto "fantasia sexual" masculina.

${ }^{13}$ A autora refere-se à dimensão performativa do gênero e não da idade. Mas as suas formulações podem ser apropriadas, aqui, para pensar os processos de construção das categorias etárias. 
Analisando um portal pornográfico denunciado, o APF Alfredo mostra-me que algumas meninas que pareciam menores na imagem da primeira página, não parecem ser nas imagens seguintes. São meninas bem jovens com corpos magros, seios pequenos, poucas curvas, pelo pubiano ralo ou depilado, usando roupas e representando performances infantis que fazem o estilo "Lolita", ou seja, inocentes, porém provocantes. Segundo o agente, uma análise mais minuciosa permite perceber a diferença entre a menoridade simulada $e$ as imagens que são inquestionavelmente de menores, apesar de reconhecer que nem sempre é possível ter certeza se as/os jovens são menores ou se têm um pouco mais de 18 anos.

Os parâmetros estéticos utilizados pelos agentes para caracterizar a menoridade na análise das imagens constituem um conjunto de elementos bem variados, como o tamanho das pernas e outros membros do corpo, forma da cabeça, performance etc. Analisando outra denúncia de uma página pornográfica na internet, Richard mostra-me que algumas meninas têm rostos de crianças e corpos de mulheres ou vice-versa. Ele só considera menor se reunir as duas coisas. As "japas" (nipônicas) são entendidas pelos agentes como uma categoria à parte, enquanto corpos impossíveis de categorizar pelos critérios ocidentais comuns de sensibilidade em relação à idade, pois elas não têm seios, nem formas (curvas) e nem pelos.

Além disso, como propõe Goffman (1959:74), "ser uma determinada espécie de pessoa não consiste meramente em possuir os atributos necessários, mas também em manter os padrões de conduta e aparência que o grupo social do indivíduo associa a ela". Por isso, principalmente nos vídeos, a aparência de "discernimento" na performance sexual também é levada em conta para caracterização da menoridade.

Analisando junto com o APF Alfredo uma denúncia, achei, pelo rosto e pelo corpo da menina, que ela fosse menor. Ele, inicialmente, discordou, argumentando que ela parecia estar compreendendo o que estava acontecendo, sabia como agir na 
situação e também estaria aproveitando. Era um vídeo de uma menina tendo relação sexual com três jovens, simultaneamente. Alfredo já estava escrevendo a informação sobre a denúncia quando reviu a cena e mudou de ideia. Ele comenta que não acha mais que ela tenha tanto "discernimento". Apesar de não parecer nada "forçado", "violento", ela parece "meio perdida" $e$ "ri nervoso". A partir disso, o agente reconsidera sua primeira impressão e escreve que a menina parece menor.

No caso de dúvida quanto ao caráter pornográfico da cena e quanto à menoridade das pessoas envolvidas, não se instaura um inquérito. Pergunto a um delegado que coordena o núcleo de combate à pornografia infantil no órgão central da Polícia Federal, em Brasília, se é o princípio do in dubio, pro reu que guia essa decisão. Ele diz que não, que esse princípio é válido no processo judicial. Na fase da investigação policial, é o contrário: in dubio pro societate. O delegado explica que esse critério de seleção é baseado em uma decisão pragmática, uma economia de tempo, que leva a priorizar as investigações que têm maior probabilidade de dar certo. Foi o mesmo motivo exposto pelos agentes do NUNET. "Não adianta nada trabalhar e no final morrer na praia. Porque o perito vai dizer: não há como confirmar que a criança é efetivamente menor de idade. Então, a gente nem perde tempo", afirma o APF Richard.

Depois de configurada a "materialidade", o delegado instaura o inquérito policial, voltado para a identificação da "autoria" do crime. Para isso, o primeiro passo é identificar o endereço IP (internet protocol) do usuário de um programa de compartilhamento de arquivos ponto-a-ponto, como o eMule, ou de criação de uma página, como um perfil do Orkut. Os policiais têm algumas técnicas de rastreamento que permitem identificar os IPs, que não podem ser divulgadas, pois fazem parte do que eles chamam de "caixa preta" da investigação. Depois de identificado o número IP, o delegado encaminha um pedido para a Justiça Federal de "quebra de sigilo telemático", visando obter, junto aos provedores de acesso, o endereço físico de onde partiu a conexão, 
onde será feita uma operação de busca e apreensão de computadores e demais mídias em que possam ser armazenadas as imagens (CDs, DVDs, câmeras fotográficas, pen drives etc.).

Durante as buscas e na presença de duas testemunhas, os policiais preenchem um documento ("auto circunstanciado"), nos quais descrevem todo o material apreendido, além de apurar informações relevantes sobre a localização, pertencimento $e$ usuários dos computadores e demais objetos apreendidos. A seguir, o material é levado para a delegacia, onde é preenchido o "auto de apreensão", e encaminhado para análise pericial, realizada por peritos de informática do Núcleo de Criminalística (NUCRIM) da PF. A perícia é a fase do inquérito na qual é realizada a avaliação conclusiva em relação à "materialidade" e à "autoria". O laudo visa responder se foi encontrado no material apreendido imagens de pornografia infantil, se há indícios de que esse material tenha sido divulgado na internet a partir daquele computador e se é possível identificar indícios de autoria.

Caso esses indícios de "materialidade" e "autoria" sejam constatados na análise pericial, o "alvo" é "indiciado" pelo delegado. A partir do "indiciamento" é que a pessoa investigada passa a constar como "ficha suja", ou seja, passa a constar na sua folha de antecedentes criminais (FAC) que ela está sendo investigada criminalmente. Por fim, a autoridade policial faz um relatório concluindo o inquérito e o encaminha ao Ministério Público Federal para que o Procurador da República avalie se os indícios são suficientes para oferecer uma denúncia que, se for aceita pelo Juiz Federal, dará início a uma ação penal pública, isto é, a um processo judicial.

Como propõe Becker (1973), a acusação é central para a passagem dos atos transgressivos para as identidades desviantes. Sendo assim, como instrumento de acusação, o inquérito policial é central para o processo de construção social do "pedófilo" enquanto criminoso que é responsabilizado legalmente por atos que designam uma condição "doentia" ou "anormal". 


\section{Entre monstros e bem feitores}

Como vimos, o enfrentamento político da "pedofilia na internet" é marcado por uma forte dramaticidade e por uma série de imperativos morais. Inspirada pela noção de Bailey (1983) sobre os "usos táticos das paixões", mais do que apresentar uma análise racional em oposição a uma abordagem emotiva do tema, neste artigo procurei destacar a importância do efeito moral do discurso das emoções e da sensibilização estética por meio da descrição e exibição das imagens de pornografia infantil - que incitam "pena", "horror" e/ou "ódio" - e o seu papel crucial na produção das percepções sociais sobre "monstruosidade" $e$ "vitimização".

Com o objetivo de ilustrar como o combate à "pedofilia" é construído como uma "causa" coletiva e unânime, tomei como objeto de análise a CPI da Pedofilia, no Senado Federal, e os inquéritos da Polícia Federal em torno da pornografia infantil na internet. Procurei mostrar as estratégias e os desdobramentos da denúncia em cada um desses espaços e as suas interconexões. Como vimos, enquanto na CPI a denúncia é convertida em uma "causa" política que une a todos contra a "pedofilia", no inquérito policial, a denúncia é transformada em "caso" de polícia e visa produzir uma ação penal pública com o intuito de responsabilizar criminalmente um indivíduo. Em relação às estratégias, observa-se, no espaço político, a centralidade das emoções para a produção de um engajamento coletivo e, na investigação policial, a atenção desloca-se do engajamento de um denunciante indignado para a análise dos fatos e a identificação de um culpado.

Vimos também que, no processo de construção da "causa" política conduzido pela CPI, o "pedófilo" emerge como uma figura monstruosa dessingularizada, um inimigo comum contra o qual os "homens de bem" se reúnem. No processo de incriminação conduzido através das investigações e dos inquéritos policiais, a direção é justamente oposta, levando à individualização da figura genérica do "pedófilo" através da identificação e acusação criminal 
de um "alvo" ao qual podem ser atribuídos atos tipificados pela lei penal. $\mathrm{O}$ encontro entre essas duas estratégias garantiu simultaneamente a espetacularização do monstro exemplar e a proliferação de monstros cotidianos ou empalidecidos.

É importante atentar ainda para uma outra diferença entre o inquérito parlamentar $e$ o inquérito policial no que se refere ao destinatário da denúncia. Na CPI, a espetacularização do horror visa persuadir e mobilizar tanto o público mais imediato de parlamentares e outros representantes da administração pública quanto o espectador à distância, o cidadão comum, o possível eleitor, o que requer a mediação dos meios de comunicação de massa. No inquérito policial, a acusação se destina ao Procurador da República (responsável por arquivar o procedimento ou oferecer a denúncia, dando início ao processo judicial) e em, última instância, pretende convencer o Juiz de Direito. Se as estratégias e os efeitos da construção social da "pedofilia" na CPI $e$ na Polícia Federal podem ser separados para fins analíticos, procurei mostrar também que, na prática, eles se interpenetram.

A comissão parlamentar de inquérito não pretende apenas sensibilizar o público, mas também é fortemente marcada por um caráter acusatório enquanto produtora de leis penais e parceira dos órgãos de persecução penal no combate à pornografia infantil na internet. No inquérito policial, por sua vez, o sucesso da acusação criminal não pode ser atribuído somente aos "fatos objetivos", mas também à sensibilidade dos agentes que examinam e classificam corpos, comportamentos e imagens. Além disso, a atuação policial não pretende apenas acusar e punir indivíduos, mas também ter um caráter de exemplaridade e um efeito de vigilância contínua e generalizada, contribuindo para prevenir que outros crimes sejam cometidos.

Sendo assim, tanto a CPI da Pedofilia quanto os inquéritos da Polícia Federal têm efeitos de acusação e de sensibilização. Como destaca Boltanski (1993), a mobilização do engajamento através do sentimento convoca a atenção do espectador para o bem feitor ("homens de bem"), enquanto o engajamento a partir 
da denúncia e da acusação convoca a atenção para o culpado (o "pedófilo" criminoso). Em ambos os casos, há o apagamento da vítima em favor das causas e a figura da "criança abusada" comparece como suporte para denúncia e sensibilização a partir do qual emergem, de um lado, o "pedófilo" $e$, de outro, os representantes dos "homens de bem" e guardiões da infância.

Uma denúncia instaura um sistema de relações entre quatro actantes: aquele que denuncia, aquele contra quem a denúncia é feita, aquele a quem ela se destina e aquele em favor de quem a denúncia é feita (Boltanski et al, 1984:6). Analisei as estratégias de legitimação da figura do denunciante, de construção do culpado $e$ de mobilização do engajamento do destinatário da denúncia. Falta, portanto, compreender como a denúncia pretende proteger aquele que é ameaçado: a "criança", que é o sujeito ou o "bem jurídico" tutelado pela lei que criminaliza a pornografia infantil.

Como foi exposto, é muito raro identificar as crianças que aparecem nas imagens assim como seus "abusadores", o que seria necessário para protegê-las de modo mais imediato ao cessar os "abusos". Portanto, é preciso existir uma lógica que permita construir uma ligação de causa e efeito entre a conduta do consumidor e do difusor de imagens de pornografia infantil (que são os principais "alvos" atingidos por essa "cruzada antipedofilia") e o sofrimento da "criança abusada".

A lógica que associa as condutas da maioria" dos "alvos" dos inquéritos sobre pornografia infantil na internet ao sofrimento das vitimas é: crianças são abusadas e essas imagens são produzidas em larga escala porque existe um mercado consumidor que se excita com esse tipo de imagem. Minha hipótese é que esses criminosos são responsabilizados não tanto pelo que eles fazem (divulgar, trocar, distribuir ou adquirir, possuir, armazenar imagens), mas pelo que suas ações revelam sobre seus desejos e

\footnotetext{
${ }^{14}$ Refiro-me aos inquéritos que tratam do crime de posse e de divulgação de pornografia infantil na internet e não daqueles raros casos nos quais se localiza o "abusador" das crianças e produtor das imagens.
} 
sobre os perigos que estes representam. A meu ver, esse é um dos principais motivos que explica porque geralmente não se faz muita distinção entre o fenômeno da pornografia infantil na internet e a "pedofilia".

Vale acrescentar que, diferentemente do "problema social" da "prostituição infantil", por exemplo, que é associado à vitimização, principalmente, de meninas pobres em torno da "adolescência" e da "pré-adolescência" (recortes de gênero, classe e faixa etária), o "problema" da "pedofilia" construído em torno da circulação de imagens de pornografia infantil - assim como ocorre com a temática do "abuso sexual infantil" ${ }^{15}$ - não tem um perfil de vítima determinado, podendo representar "qualquer criança", o que o torna particularmente ameaçador. Meninos e meninas das mais variadas idades (desde bebê até a puberdade) e origens sociais e étnicas aparecem em vídeos $e$ fotos em diferentes modalidades de cenas eróticas: sexo oral, vaginal e anal, meninas de tenra idade fazendo performances eróticas e se masturbando, crianças sendo molestadas ou estupradas por adultos, várias crianças juntas interagindo sexualmente, homens adultos ejaculando no rosto ou na genitália de crianças etc.

As imagens convocam no espectador, simultaneamente, sentimento de piedade e de horror. Sugiro que, se diante do sentimento de piedade, as crianças "abusadas" que aparecem nas cenas pornográficas podem ser entendidas como "sujeitos objetificados e subordinados", isto é, como "vítimas de violência", frente ao sentimento de "horror" elas emergem predominantemente como crianças "pervertidas" e perigosamente sexualizadas. Com isso, elas são percebidas não apenas como "infâncias em perigo", mas também como "infâncias perigosas", nos termos de Donzelot (1980), pois, ao serem deslocadas para um território erótico no qual não deveriam estar, elas participam, ao lado do "pedófilo", da poluição da noção de infância. Desse

${ }^{15}$ Sobre a construção social do "problema" do "abuso sexual infantil", ver Hacking (1992). 
modo, sugiro que a "cruzada antipedofilia" protege menos as crianças de "carne osso" que aparecem nas cenas pornográficas do que o ideal de "infância pura e inocente", ameaçado pelas imagens de infâncias monstruosas. ${ }^{16}$

Essas imagens tornaram-se particularmente ameaçadoras na medida em que começaram a invadir e a ameaçar a segurança dos lares, reduto sagrado das famílias: "a imagem do pedófilo etéreo insinuando-se na casa da família, a fortaleza da segurança, inocência e domesticidade"17 (Jenkins, 1998:214). Através da internet, as cenas eróticas envolvendo crianças podem ser enviadas, recebidas e acessadas de qualquer computador, tanto por adultos quanto por crianças e adolescentes que navegam em diferentes sítios on-line ou que utilizam ferramentas de bate-papo para conversar com pessoas que conheceram, muitas vezes, no próprio "mundo virtual".

Como apontam diferentes estudiosos do tema (Tate, 1990; Hacking, 1992; Jenkins, 2001; Taylor e Quayle, 2003), longe de ser simplesmente uma atividade sexual solitária, a pornografia infantil pode servir também como um instrumento de troca e socialização entre pessoas que sentem atração sexual por crianças ou por material pornográfico "extremo", bem como de validação e normalização de suas formas de excitação e satisfação erótica.

\footnotetext{
${ }^{16}$ A ideia de que as crianças na "pornografia infantil" podem ser compreendidas como a representação de infâncias monstruosas fica particularmente evidente em um pronunciamento do presidente da CPI da Pedofilia no plenário do Senado Federal. Ao se referir às "vítimas" que aparecem nas cenas de sexo, Magno Malta exclama: "meninas e meninos de 7 anos de idade, viciados no sexo. Mexeram na sua libido! Criaram verdadeiras taras e fizeram monstros de crianças de 8, 10 anos de idade".

${ }^{17} \mathrm{O}$ autor lembra que pouco mais do que uma década antes, autoras feministas argumentavam que o quarto e o lar eram precisamente o lócus da maioria dos abusos sexuais e que os perpetradores eram geralmente os pais e irmãos das vítimas. Nos anos 1990, essa percepção praticamente desapareceu no contexto político norte-americano, de modo que ideias acerca da ameaça sexual às crianças foram submetidas a uma importante maré de mudanças (Jenkins, 1998:214).
} 
Pode ser utilizada também na intimidação das vítimas para preservação do silêncio e continuidade dos contatos "abusivos" ou como ferramenta pedagógica para dessensibilizar e desinibir crianças durante o processo de "grooming" ${ }^{18}$, de maneira a encorajá-la a normalizar e a reproduzir as atividades sexuais representadas.

Portanto, para compreender a ameaça que as imagens de pornografia infantil representam socialmente não se pode considerar apenas o dano individual causado às "crianças abusadas" que nelas aparecem ou mesmo a possibilidade dos vídeos ou das fotos serem fruto ou ferramenta para o assédio online de menores. Ao lado das diversas modalidades de "vitimização", outro perigo talvez resida justamente no medo de "contágio" ou naturalização dos prazeres dissidentes (Díaz-Benitez e Fígari, 2009) representados nas imagens. As crenças no "contágio perigoso" (ou contaminação perversa) revelam que existe uma forte preocupação em conter a transmissão do "mal que se adivinha" (Vianna, 1999), resultante da difusão viral, através da internet, de cenas antes praticamente invisíveis e impensáveis ou restritas a um universo desviante bastante isolado. ${ }^{19}$ Nesse sentido, sugiro que a "pedofilia" é socialmente entendida e tratada não apenas como a causa da proliferação da pornografia infantil na internet, mas como um de seus perigosos efeitos.

\section{Referências bibliográficas}

BAILEY, Frederick George. The tactical uses of passions. Ithaca and London, Cornell University Press, 1983.

BECKER, Howard. Outsiders: studies in the sociology of deviance. New York, The Free Press, 1973.

${ }^{18}$ O termo inglês - que pode ser literalmente traduzido como "preparação" - é utilizado para se referir ao processo que vai da aproximação sedutora do "pedófilo" na internet (muitas vezes disfarçado de criança) ao abuso sexual da vítima.

${ }^{19}$ Para uma narrativa a respeito de como imagens de pornografia infantil eram difundidas e trocadas antes da "era da internet" a partir de revistas especializadas e fotografias trocadas clandestinamente através do correio, ver Tate (1990). 
O monstro contemporâneo

BOltANSKI, Luc; DARRÉ, Yann; SCHILTZ, Marie-Ange. La dénonciation. Actes de la recherche en sciences sociales, n51, mars 1984, pp.3-40.

. La Souffrance à Distance: Morale humanitaire, médias et politique. Paris, Éditions Métailie, 1993.

BOURDIEU, Pierre. A representação política: elementos para uma teoria do campo político. In: O Poder Simbólico. Lisboa, 1989, pp.163-207.

. "É possível um ato desinteressado?" In: Razões Práticas: sobre a teoria da ação. Campinas, Papirus, 1996, pp.137-161.

BRASIL. Constituição da República Federativa do Brasil (CF), 1988. (CPP), 1941.

. DECRETO-LEI No 3.689/1941. Código de Processo Penal . LEI No 8.069, de 13 de julho de 1990. Estatuto da Criança e do Adolescente (ECA), 1990.

BUTLER, Judith. Problemas de gênero: feminismo e subversão da identidade. Rio de Janeiro, Civilização Brasileira, 2003.[Tradução de Renato Aguiar]

CARRARA, Sérgio. Tributo a Vênus: a luta contra sífilis no Brasil, da passagem do século aos anos 40. Rio de Janeiro, FIOCRUZ, 1996.

DíAz-BeniteZ, Maria Elvira e FÍGARI, Carlos Eduardo (org.). Prazeres Dissidentes. Rio de Janeiro, Garamond, 2009.

DOnZelot, Jacques. A Polícia das famílias. Rio de Janeiro, Edições Graal, 1980. [Tradução de AlBUQUERQUE, M. T. D. C.]

DSM IV-TR -Manual diagnóstico e estatístico de transtornos mentais, 2002. 4a edver, Porto Alegre, Artmed. [Tradução: Cláudia Dornelles]

FouCAUlt, Michel. Os Anormais. São Paulo, Martins Fontes, 2001. [1975]

GOFFMAN, Erving. The presentation of self in everyday life. NY, Doubleday Anchor Books, 1959.

HACKING, Ian. World-making by kind-making: child abuse for example. In: Hull, M. D. D. (ed.). How classification works (Essays in honour of Nelson Goodman). Edinburgh, Edinburgh University Press, 1992, pp.180-238. 
JENKINS, Philip. Beyond Tolerance: child pornography on the internet. New York and London, New York Universty Press, 2001.

. Moral Panics: changing concepts of the child molester in modern America. New Haven and London, Yale University Press, 1998.

LOWENKRON, Laura. O Monstro Contemporâneo: a construção social da pedofilia em múltiplos planos. Tese de doutorado em Antropologia Social, Museu Nacional, UFRJ, Rio de Janeiro, 2012.

. "Abuso sexual infantil, exploração sexual de crianças, pedofilia: diferentes nomes, diferentes problemas?" Sexualidade, Saúde e Sociedade Revista Latino-Americana $\mathrm{n}^{\circ}$ 5, América do Norte, ago 2010, pp.9-29.

MAUSS, Marcel. A expressão obrigatória dos sentimentos. In: FIGUEIRA, Sérvulo (org). Psicanálise e Ciências Sociais. Rio de Janeiro, Francisco Alves, 1980, pp.56-63.

OMS. Classificação Estatística Internacional de Doenças e Problemas relacionados à Saúde, Décima Revisão - CID-10. Organização Mundial de Saúde (OMS). São Paulo, Edusp, 1998.

SIMMEL, Georg. The sociology of secrecy and of Secret Societies. In: TIRYAKIAN, E. A. (ed). On the margin of the visible: sociology, the esoteric and the occult. New York, John Wiley \& Sons, 1974, pp.7992. [1906]

SonTAG, Susan. Diante da Dor dos Outros. São Paulo, Companhia das Lestras, 2003. [Tradução de FIGUEIREDO, R.]

TATE, Tim. Child Pornography: an investigation. London, Methuen, 1990.

TAYlOR, Max; QuAYle, Ethel. Child Pornography: an internet crime. New York, Routledge, 2003.

VIANNA, Adriana de Resende Barreto. O Mal que se adivinha: polícia e menoridade no Rio de Janeiro. Rio de Janeiro, Arquivo Nacional, 1999. 